\title{
Management of Tear Trough with Hyaluronic Acid Fillers: A Clinical-Practice Dual Approach
}

\author{
Fernando Urdiales-Gálvez' \\ Lisandro Farollch-Prats ${ }^{2}$ \\ 'Instituto Médico Miramar, Málaga, Spain; \\ ${ }^{2} \mathrm{Nu}$ Clinic, Barcelona, Spain
}

Introduction: Tear trough deformity (TTD) is currently a major concern for many individuals that seek periorbital rejuvenation. Among the different options currently available for treating TTD, hyaluronic acid (HA) filler injections have become increasingly popular.

Purpose: To provide a dual approach, direct and indirect strategies for treating TTD with HA fillers according to patient facial structure.

Methods: The current paper combined the authors' experience with the currently available scientific evidence.

Results: The current study presents the authors clinical experience regarding TTD treatment and serves as a guide on the best therapeutic approach with HA fillers. For achieving good aesthetic outcomes, especially in TTD, it is crucial to have a detailed understanding of both facial anatomy and the individual characteristics of the HA fillers. Proper management of full-face facial rejuvenation should have into consideration three main pillars: structure, contour, and refinement.

Conclusion: Treatment of TTD should be addressed from a comprehensive perspective, including potential lack of structural support, as well as interventions on the dynamic processes involved in the problem. Additionally, HA fillers can be used to modulate mechanically muscle movement by either facilitating their action or decreasing contractility by reducing their movement. Clinicians can benefit from ongoing guidance on the use of these products in order to tailor and optimize treatments to patient's requirements. Although HA filler injections have low rates of side effects, TTD was listed as the most challenging area to treat with HA. Therefore, TTD treatment should be performed only by well-trained and experienced specialists.

Keywords: tear trough deformity, hyaluronic acid, MD Codes, MD Dyna Codes, cohesivity, periorbital region

\section{Introduction}

Periorbital lipoatrophy may be defined as a natural consequence of the anatomic attachments of the periorbital tissues. ${ }^{1}$ It consists of a physiological process of supraperiosteal and subcutaneous fat loss that is noticeable as a result of inherited anatomical differences and aging. ${ }^{1}$

Despite being of an important cosmetic concern, the exact etiology of the tear trough deformity (TTD) has not been well defined. However, different factors, such as gender (there are differences between men and women), congenital or agerelated maxillary hypoplasia, laxity of the retaining ligaments of the periorbital area, cutaneous elastosis, structural changes in deep and/or superficial fat compartments, and a certain genetic predisposition have been proposed. ${ }^{1-3}$ 
Multiple classification systems have been introduced to provide an objective means of evaluating the TTD and to aid the aesthetic medicine specialists in choosing appropriate treatment options. ${ }^{4-8}$

Over the last several years, there has been considerable interest in nonsurgical treatment of the TTD using injectable products, such as hyaluronic acid (HA). ${ }^{9}$ Among the different therapeutic strategies, the MD Codes $^{\circledR}$ (Codes) represent specific anatomical subunits for injection of HA fillers. ${ }^{10}$ Additionally, HA fillers can be used to modulate mechanically muscle movement by either facilitating their action, via a lever or pulley effect, or decreasing contractility by reducing their movement. ${ }^{11}$

The purpose of this paper is to provide two different treatment strategies for addressing tear trough deformity, with HA fillers, depending on patient's facial structure.

\section{Methods}

The current study presents the clinical experience of the authors regarding TTD treatment, as well as an overview of the current evidence.

Patients signed written informed consent before treatment. Patients were fully informed about procedure, including side effects and potential complications. All procedures were carried out in accordance with the tenets of the Declaration of Helsinki. Study protocol was approved by the ethics committee of Instituto Médico Miramar.

\section{Classification of TTD}

Different classification systems have been proposed with the purpose of providing an objective method for assessing the TTD and selecting the best treatment options. ${ }^{4-8}$

Barton et $\mathrm{al}^{4}{ }^{4}$ in an effort to analyze objectively their postoperative results, proposed a grading system based on anatomic analysis (Table 1).

Hirmand proposed a classification system of the TTD based on clinical evaluation. According to this classification, the TTD might be addressed into three different types: Class I, II, and III (Table 1, Figure 1). ${ }^{5}$

There are currently two classification systems that evaluate the type of TTD and guide us on the best therapeutic approach with HA fillers. ${ }^{4,7}$

Belhaouari et $\mathrm{al}^{7}$ proposed a classification that integrated both the semiological analysis and the therapeutic strategy (Tables 1 and 2). According to this classification, the TTD might be addressed into two ways: Direct one, which is indicated in the stages $2 \mathrm{~A}$ and $3 \mathrm{~A}$; and an Indirect one that was proposed for the stages $1 \mathrm{~A}, 1 \mathrm{~B}, 2 \mathrm{~B}$, and $3 \mathrm{~B} .^{7,8}$

Classification systems are mainly based on anatomic analysis (Figure 1, Tables 1 and 2).

\section{Treatment}

Treatment strategy is based on the MD Codes ${ }^{\circledR}$, which were developed by Mauricio de Maio. ${ }^{10,11}$

Myomodulation makes reference to the mechanic effect of HA on muscle function. ${ }^{10-12}$ It is based on myotatic reflex, which causes muscle contraction after the muscle is stretched. ${ }^{10-12}$ According to this theory, if

Table I Tear Trough Deformity Classification Systems.

\begin{tabular}{|c|c|c|}
\hline Barton et $\mathrm{al}^{4}$ & Hirmand $^{5}$ & 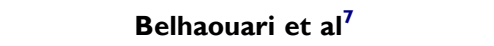 \\
\hline $\begin{array}{l}\text { - Grade 0: Absence of medial or lateral lines } \\
\text { demarcating the arcus marginalis or the } \\
\text { orbital rim and a smooth, youthful contour } \\
\text { without a transition zone at the orbit-cheek } \\
\text { junction. } \\
\text { - Grade I: Mild, subtle presence of a medial } \\
\text { line or shadow; smooth lateral transition of } \\
\text { lid-cheek junction. } \\
\text { - Grade II: Moderate prominence of a visible } \\
\text { demarcation of the lid-cheek junction, } \\
\text { extending from medial to lateral. } \\
\text { Grade III: Severe demarcation of the orbit- } \\
\text { cheek junction, with an obvious step } \\
\text { between the orbit and the cheek. }\end{array}$ & $\begin{array}{l}\text { - Class I patients have volume loss limited } \\
\text { medially to the tear trough. These patients } \\
\text { can also have mild flattening extending to the } \\
\text { central cheek. } \\
\text { - Class II patients exhibit volume loss in the } \\
\text { lateral orbital area in addition to the medial } \\
\text { orbit, and they may have moderate volume } \\
\text { deficiency in the medial cheek and flattening } \\
\text { of the central upper cheek. } \\
\text { - Class III patients present with a full depres- } \\
\text { sion circumferentially along the orbital rim, } \\
\text { medial to lateral. }\end{array}$ & $\begin{array}{l}\text { - Stage IA: insufficient volume without } \\
\text { ptosis } \\
\text { - Stage IB: insufficient volume with ptosis } \\
\text { - Stage } 2 \mathrm{~A} \text { : normal volume without ptosis } \\
\text { - Stage } 2 \mathrm{~B} \text { : normal volume with ptosis } \\
\text { - Stage } 3 \mathrm{~A} \text { : Increased volume without } \\
\text { ptosis } \\
\text { - Stage 3B: Increased volume with ptosis. }\end{array}$ \\
\hline
\end{tabular}

Note: Data from these studies. ${ }^{4,5,7}$ 

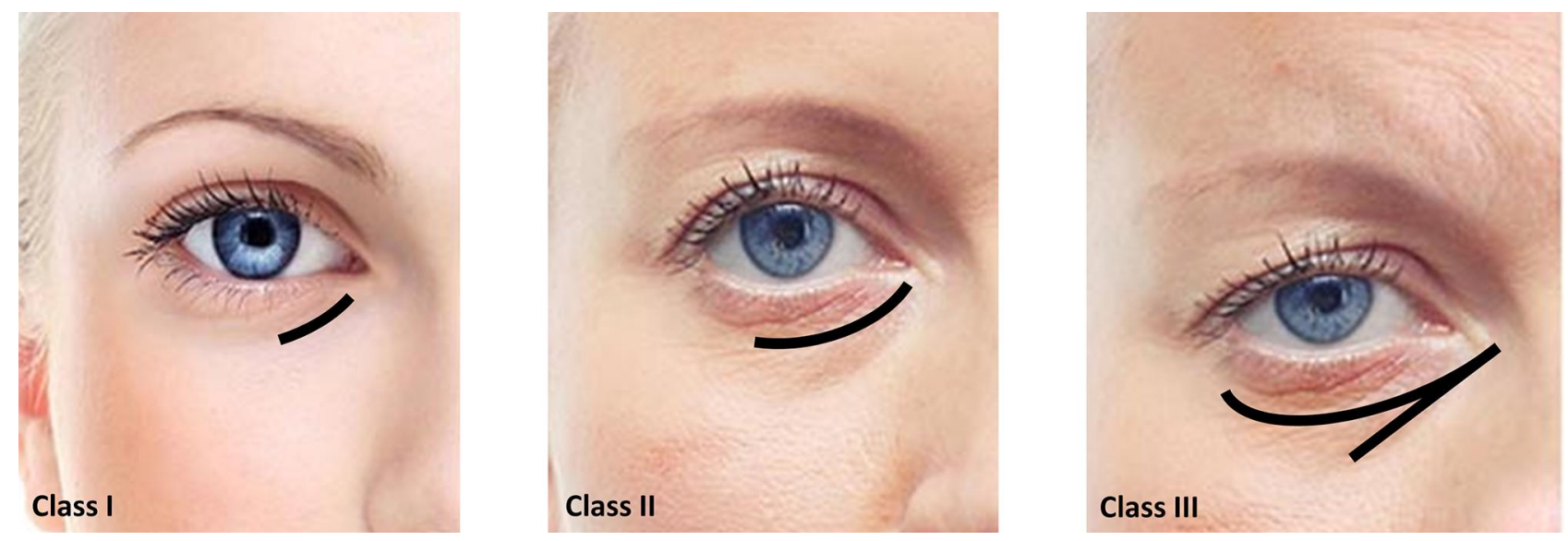

Figure I Hirmand classification of tear trough deformity. Data from Hirmand. ${ }^{5}$

there is a structural deficiency (either congenital or agingrelated) and muscle contraction is weakened, HA filler placed under the muscle provides support and improves tensile strength by increasing distance between the origin and insertion, which increases mechanical advantage and facilitates the action of the muscle. ${ }^{10-12}$ On the contrary, if the muscle action is excessive, injecting HA filler above the muscle or directly into or beneath the muscle near its

Table 2 Belhaouari et al $^{9}$ Tear Trough Classification System According to the Volume and the Ptosis with the Treatment Strategy with Hyaluronic Acid Filler

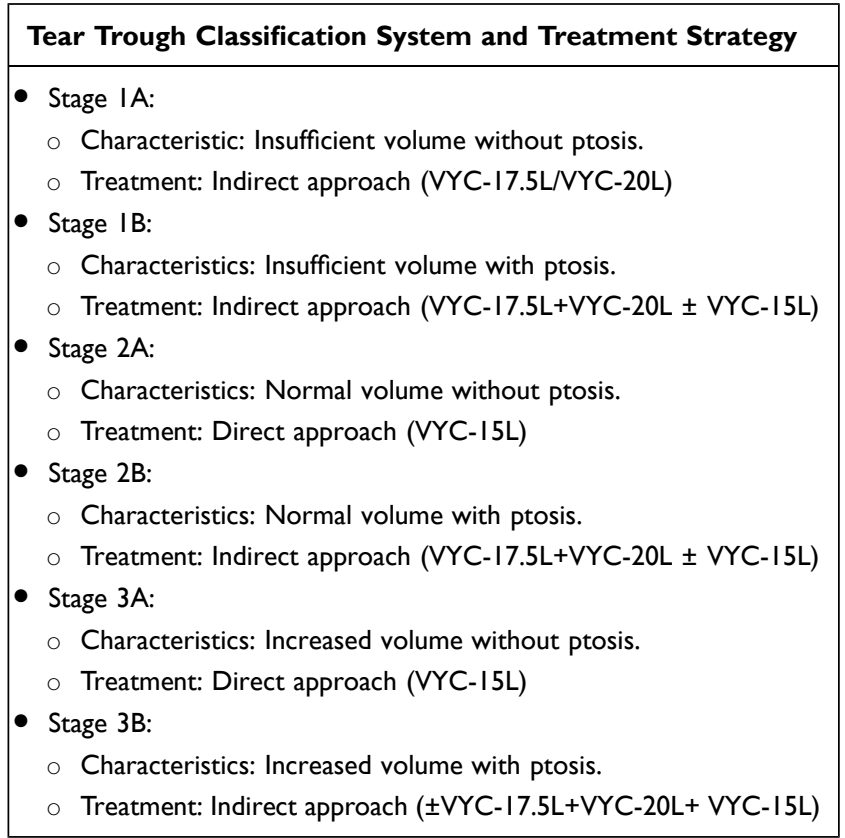

Abbrevaition: VYC, Vycross technology. origin or insertion creates a mechanical obstacle to the muscle action. $^{10-12}$

An overview of the action of HA fillers on the action of the different facial muscles is summarized in Figure 2. Additionally, Table 3 shows the mechanic myomodulation effect with HA filler on the different treatment points.

Table 4 summarizes different HA injectable fillers used for the aesthetic management of the TTD in this article.

\section{Therapeutic Strategy}

TTD treatment should not be restricted to the groove itself. It would be advisable to contemplate a comprehensive approach of the problem, which includes potential lack of structural support, as well as interventions on the dynamic processes involved in the problem.

Based on Hirmand, ${ }^{5}$ Belhaouari ${ }^{7}$ classifications, and facial lipoatrophy, ${ }^{13}$ we attempt to do a comprehensive approach for treating TTD that may help clinicians to treat this challenging area.

Table 5 shows different recommendations of the authors.

A proper diagnosis of the TTD is essential to address the right treatment strategy.

From a clinical point of view, the recommended therapeutic strategy of the tear trough deformity would be (Table 6):

- Direct approach (stages 2A and 3A of the Belhaouari classification system): Central infraorbital (Tt1) + Lateral infraorbital $(\mathrm{Tt} 2)+$ medial infraorbital $(\mathrm{Tt} 3)$ (Figure 3).

- Indirect approach (stages 1A,1B, 2B, and 3B of the Belhaouari classification system): Anterior temple 


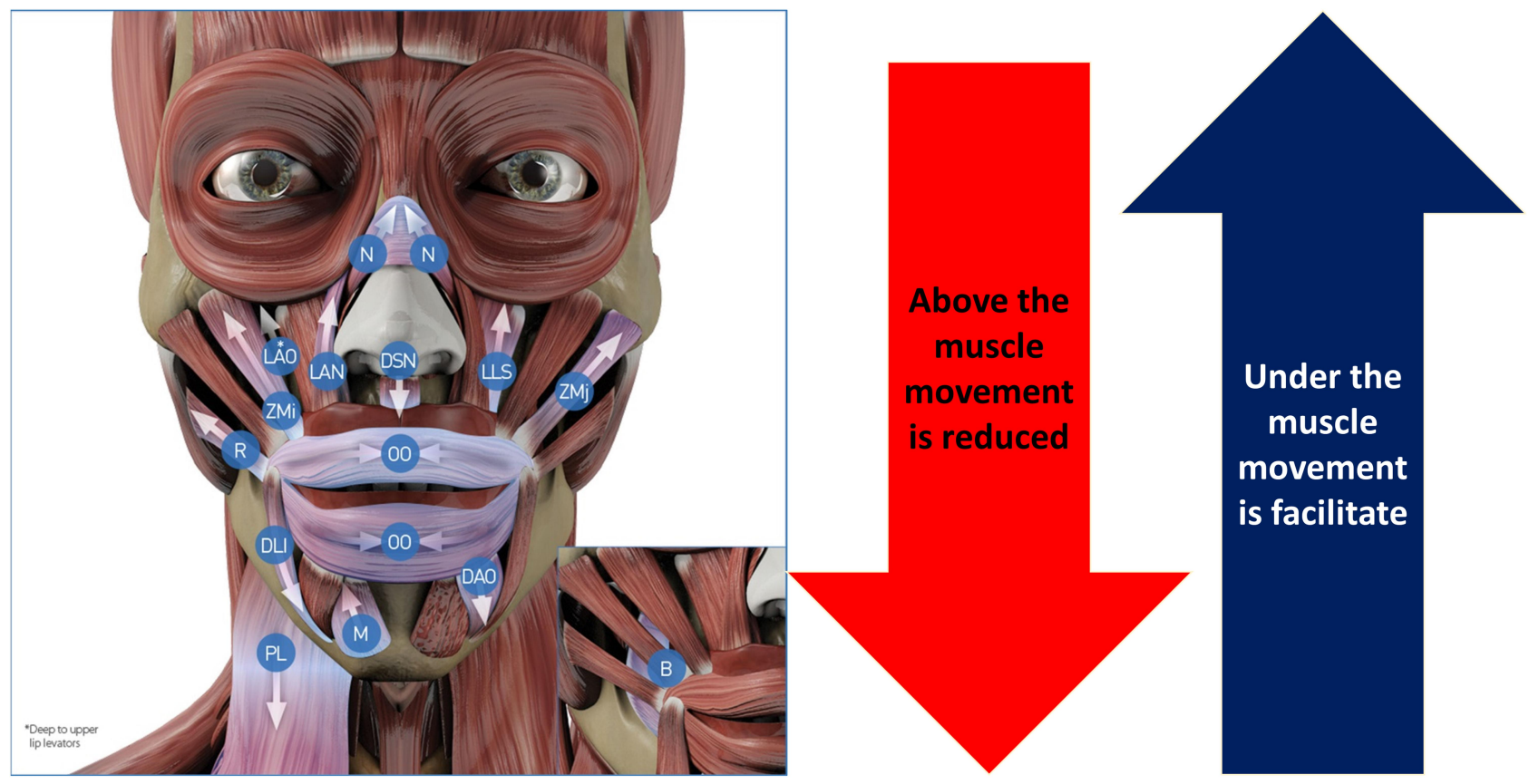

Figure 2 Overview of the hyaluronic acid (HA) injectable filler on the muscle activity. Data from de Maio." Image courtesy from and reprinted with permission from Allergan plc, Dublin, Ireland.

Abbreviation: N, nasalis; LAN, levator labii superioris alaeque nasi; LLS, levator labii superioris; LAO, levator anguli oris; ZMj, zygomaticus major; ZMi, zygomaticus minor; DSN, depressor septi nasi; DAO, depressor anguli oris; DLI, depressor labi inferiores; $\mathrm{B}$, buccinator; $\mathrm{R}$, risorius; PL, plastisma; OO, orbicularis oris; M, mentalis.

(T1) + Zygomatic arch (Ck1) + Zygomatic eminence $(\mathrm{Ck} 2)+$ Anteromedial cheek $(\mathrm{Ck} 3)+$ Lateral lower cheek/parotid area $(\mathrm{Ck} 4)+$ Submalar/buccal area $(\mathrm{Ck} 5)+\mathrm{Tt} 1+\mathrm{Tt} 2+\mathrm{Tt} 3+$ Central lateral orbital $(\mathrm{O} 1)+$ Lower lateral orbital $(\mathrm{O} 2)+$ Upper lateral orbital (O3) (Figure 4).

Figures 3 and 4 summarize the different treatment strategies.

\section{Results}

\section{Direct Approach}

The proper technique for a direct approach of tear trough area and palpebro-malar area is to use HA fillers of mid to low density, elasticity, and cohesiveness, and additionally, with a mid to low water retention capacity. HA should be administered in small boluses with a 25/27 G blunt cannula, performing always an aspiration maneuver before injecting the filler, 10,11 (Figure 5).

The direct approach to this area is indicated when patients present negative snap-tests and have a normal or excessive suborbicularis oculi fat pad (SOOF) volume. In other words, those subjects classified as stages 2 and 3 in the Belhaouari classification or Class I in the Hirmand one (Figure 1 and Table 2).
The treatment approach consists in a bolus of HA filler in front of the orbital septum (a thin fibrous layer arising from the periosteum along the inferior and superior orbital rims), at supraperiosteal level, between the orbicularis retaining ligament and the zygomatic cutaneous ligament $^{6,11}$ (Figure 5).

The specialist must be aware of the infraorbital artery branches and of the angular artery and vein. It is important to take into account that tear trough and orbital codes should be reserved for well-trained and experienced specialists, who had received specific training in this technique and those who have an exhaustive knowledge of the anatomy and physiology for this particular area. ${ }^{10,11}$

\section{Indirect Approach}

This treatment strategy is based on the sequence: Structure-Contour-Refinement.

\section{Structure}

\section{Temporal Region}

The point that should be treated is $\mathrm{T} 1$, at the supraperiosteal level, accessing from $\mathrm{T} 1$ located at the frontosphenoidal junction, at the beginning of the temporal fossa (Figure 6). 
Table 3 Mechanic Myomodulation Effect with Hyaluronic Acid (HA) Filler on the Different Treatment Points.

\begin{tabular}{|c|c|c|}
\hline $\begin{array}{l}\text { Treated } \\
\text { Point }\end{array}$ & Location & Action \\
\hline TI & Under & $\begin{array}{l}\text { To increase tightening in temporal-orbicular and temporal-cutaneous true retaining ligaments, which cause elevation of } \\
\text { the tail of the eyebrow. }\end{array}$ \\
\hline Ckl & Under & $\begin{array}{l}\text { Myomodulation on the zygomaticus major muscle and tension of the zygomatic-cutaneous-orbicular and orbicular true } \\
\text { retaining ligaments, with canthopexy effect. }\end{array}$ \\
\hline $\mathrm{Ck} 2$ & Under & $\begin{array}{l}\text { Myomodulation on the zygomaticus minor, orbicular, and levator upper lip muscles and tightening of the zygomatic- } \\
\text { cutaneous-orbicular and orbital-malar true retaining ligaments, causing a canthopexy effect }\end{array}$ \\
\hline Ck3 & Under $^{\mathrm{a}}$ & $\begin{array}{l}\text { Myomodulation on the zygomaticus minor and levator upper lip muscles, and tightening of the zygomatic-cutaneous- } \\
\text { orbicular and orbital-malar true retaining ligaments, which cause anterior/superior projection of the cheekbone. }\end{array}$ \\
\hline Ck4 & Above & Myomodulation on zygomaticus major muscle and tightening of true orbicularis retaining ligament. \\
\hline OI & Under & Myomodulation on orbicular muscle and tightening of true orbicularis retaining ligament. \\
\hline $\mathrm{O} 2$ & Under & Myomodulation on orbicular muscle and tightening of true orbicularis retaining ligament. \\
\hline O3 & Under & Myomodulation on orbicular muscle and tightening of true orbicularis retaining ligament. \\
\hline $\mathrm{Tt}^{\mathrm{b}}$ & Under $^{c}$ & Myomodulation on orbicular muscle. \\
\hline $\mathrm{Tt}^{\mathrm{b}}$ & Under $^{c}$ & Myomodulation on orbicular muscle. \\
\hline$T t 3^{b}$ & Under $^{c}$ & Myomodulation on orbicular muscle. \\
\hline
\end{tabular}

Notes: alnto the deep and supraperiosteal fat compartment at the medial level of the malar. ${ }^{\mathrm{b}}$ The direct approach to this area is indicated when patients present negative snap-tests and have a normal or excessive suborbicularis oculi fat pad (SOOF) volume. 'Bolus of hyaluronic acid filler in front of the orbital septum, at supraperiosteal level, between the orbicularis retaining ligament and the zygomatic cutaneous ligament. Data from these studies. ${ }^{10-12}$

Abbreviations: TI, anterior temple; T2, posterior temple; CkI, zygomatic arch; Ck2, zygomatic eminence; Ck3, anteromedial cheek; Ck4, lateral lower cheek/parotid area; OI, central lateral orbital; O2, lower lateral orbital; O3, upper lateral orbital; Ttl, central infraorbital; Tt2, lateral infraorbital; Tt3, medial infraorbital.

Table 4 Overview of the Different Hyaluronic Acid (HA) Fillers Used in Tear Trough Deformity Treatment and Their Main Characteristics

\begin{tabular}{|c|c|c|c|c|c|}
\hline & VYC-25L* & VYC-20L* & VYC-I7.5L* & VYC-I5L* & VYC-I2L* \\
\hline Indication & $\begin{array}{l}\text { Restore } \\
\text { and create } \\
\text { volume of } \\
\text { the face. }\end{array}$ & $\begin{array}{l}\text { Facial } \\
\text { volume } \\
\text { restoration. }\end{array}$ & $\begin{array}{l}\text { Treatment of deep skin } \\
\text { depressions, face contouring } \\
\text { and volume restoration to } \\
\text { correct facial structural } \\
\text { defects, contour deformities } \\
\text { volume loss in the lips, cheeks, } \\
\text { chin, lower face. }\end{array}$ & $\begin{array}{l}\text { Treatment of fine lines and } \\
\text { medium-sized skin } \\
\text { depressions, enhancement and } \\
\text { pouting of the lips to correct } \\
\text { structural defects, contour } \\
\text { deformities and volume loss. }\end{array}$ & $\begin{array}{l}\text { Treatment of superficial } \\
\text { cutaneous depressions such as } \\
\text { fine lines and for } \\
\text { improvement of skin quality } \\
\text { attributes such as hydration } \\
\text { and elasticity. }\end{array}$ \\
\hline $\begin{array}{l}\text { Concentration } \\
\text { of } \mathrm{HA}\end{array}$ & $25 \mathrm{mg} / \mathrm{mL}$ & $20 \mathrm{mg} / \mathrm{mL}$ & $17.5 \mathrm{mg} / \mathrm{mL}$ & $15 \mathrm{mg} / \mathrm{mL}$ & $12 \mathrm{mg} / \mathrm{mL}$ \\
\hline $\begin{array}{l}\text { HA molecular } \\
\text { weight }\end{array}$ & Low \& high & Low \& high & Low \& high & Low \& high & Low \& high \\
\hline Duration & $\begin{array}{l}\text { Up tol8 } \\
\text { months }\end{array}$ & Up 2 years & Up to 18 months & Up I year & Up to 9 months \\
\hline
\end{tabular}

Note: *With lidocaine.

Abbreviations: VYC-25L, Volux ${ }^{\circledR}$ (Allergan plc, Dublin, Ireland); VYC-20L, Voluma ${ }^{\circledR}$ (Allergan plc, Dublin, Ireland); VYC-I7.5L, Volif ${ }^{\circledR}$ (Allergan plc, Dublin, Ireland); Volbella ${ }^{\circledR}$ (Allergan plc, Dublin, Ireland); VYC-I 2L, Volite ${ }^{\circledR}$ (Allergan plc, Dublin, Ireland); HA, hyaluronic acid. 
Table 5 Authors Recommendations for Treating Tear Trough

Recommendations
- Make the injection with the patient seated as the tear trough deformity is better visualized in this position than when the patient is lying down.
- Use low-viscosity instead of high-viscosity hyaluronic acid (HA) or non-biodegradable agents, as it can be safely injected with fewer adverse
effects.
- Avoid superficial injections to prevent the Tyndall effect, a bluish discoloration under the skin that may arise when the HA is injected too
superficially.
- The HA filler should be gently massaged for even distribution, yet avoiding massaging too strongly.
- Follow the key principle "less is more", in order to prevent bulges under the eye, it is much better to undercorrect rather than overcorrect the
tear trough area.
- It is essential to be cautious while injecting around the infraorbital foramen to avoid injury to the neurovascular bundle.
- Inject very slowly.
- Both a needle or a cannula can be used with good results. Nevertheless, blunt-tipped cannulas may be safer due to the reduced chance of
- Tamaging vessels and nerves.

Table 6 Overview of the Authors' Recommendations for Treating Tear Trough Deformity with Hyaluronic Acid (HA) Filler According to the MD $\operatorname{Codes}^{\circledR}$.

\begin{tabular}{|c|c|c|c|c|}
\hline Code & HA Filler & Amount & Administration & Level \\
\hline TI+T2 & VYC-20L/VYC-25L & 0.5 to $0.7 \mathrm{~mL}$ & 27G needle & Supraperiosteal \\
\hline $\mathrm{Ck}^{\mathrm{a}}$ & VYC-20L/VYC-25L & $0.3 \mathrm{~mL}$ & 27-30 needle & Supraperiosteal \\
\hline Ck2 & VYC-20L & 0.1 to $0.2 \mathrm{~mL}$ & 27-30G needle & Supraperiosteal \\
\hline $\mathrm{Ck}^{\mathrm{b}}$ & $\begin{array}{c}\text { VYC-20L } \\
\text { VYC-20L+VYC-17.5L }\end{array}$ & $\begin{array}{l}0.2 \text { to } 0.4 \mathrm{~mL} \\
0.3 \text { to } 0.6 \mathrm{~mL}\end{array}$ & $\begin{array}{l}27 \mathrm{G} \text { and } 30 \mathrm{G} \text { needle } \\
25 \mathrm{G}-27 \mathrm{G} \text { blunt cannula }\end{array}$ & $\begin{array}{l}\text { Supraperiosteal } \\
\text { Supraperiosteal }\end{array}$ \\
\hline Ck4 & VYC-20L & 0.5 to $0.7 \mathrm{~mL}$ & $25-27$ G blunt cannula & Deep subcutaneous \\
\hline Ck5 & VYC- $20 \mathrm{~L}$ or $V Y C-25 \mathrm{~L}^{\mathrm{c}}$ & 0.4 to $0.7 \mathrm{~mL}$ & $25-27$ G blunt cannula & Deep subcutaneous \\
\hline$O I^{d}$ & VYC-I5L or VYC-20L & $0.1-0.15 \mathrm{~mL}$ & 27-30G needle & Supreperiosteal \\
\hline$O 2^{d}$ & VYC-I5L or VYC-20L & $0.1-0.15 \mathrm{~mL}$ & 27-30G needle & Supreperiosteal \\
\hline$O 3^{d}$ & VYC-I5L or VYC-20L & $0.1-0.15 \mathrm{~mL}$ & 27-30G needle & Supreperiosteal \\
\hline Ttl & VYC-I5L & $0.1-0.2 \mathrm{~mL}$ & 27 G blunt cannula & Supreperiosteal \\
\hline Tt2 & VYC-I5L & $0.1-0.2 \mathrm{~mL}$ & $27 \mathrm{G}$ blunt cannula & Supreperiosteal \\
\hline Tt3 & VYC-I5L & $0.1-0.1 \mathrm{~mL}$ & $27 \mathrm{G}$ blunt cannula & Supreperiosteal \\
\hline
\end{tabular}

Notes: alt is possible to inject 3 microboluses of $0.1 \mathrm{~mL}$ (one in the suture notch and the other two ones to the sides). ${ }^{\mathrm{b}}$ Treatment is performed in two phases. Phase I: To inject 0.2 to $0.4 \mathrm{~mL}$ of a HA filler of $20 \mathrm{mg} / \mathrm{mL}$ (VYC-20L), at the supraperiosteal, by means $27 \mathrm{G}$ and $30 \mathrm{G}$ needles. Phase 2: Injecting 0.3 to $0.6 \mathrm{~mL}$ (with a fan technique) of VYC-20L, by means25-27G cannulas, and injecting afterwards in the same area a more superficial amount of HA (either VYC-25L or VYC-20L, according to the patient needs) under the orbicularis muscle. 'The injection of the bolus of VYC-20L or VYC-25L depends on the skin thickness and bone structure of the patient. In some patients with excessive contractility of the orbicularis muscle, it is necessary to inject, at the superficial subdermal level, a HA filler (VYC-I5L) for correcting the horizontal wrinkles. Data from these studies. ${ }^{10-12}$

Abbreviations: TI, anterior temple; T2, posterior temple; Ckl, zygomatic arch; Ck2, zygomatic eminence; Ck3, anteromedial cheek; OI, central lateral orbital; O2, lower lateral orbital; O3, upper lateral orbital; TtI, central infraorbital; Tt2, lateral infraorbital; Tt3, medial infraorbital; VYC-I5L, Volift ${ }^{\circledR}$ (Allergan plc, Dublin, Ireland); VYC-17.5L, Volbella ${ }^{\circledR}$ (Allergan plc, Dublin, Ireland); VYC-20L, Voluma ${ }^{\circledR}$ (Allergan plc, Dublin, Ireland); VYC-25L, Volux ${ }^{\circledR}$ (Allergan plc, Dublin, Ireland). 


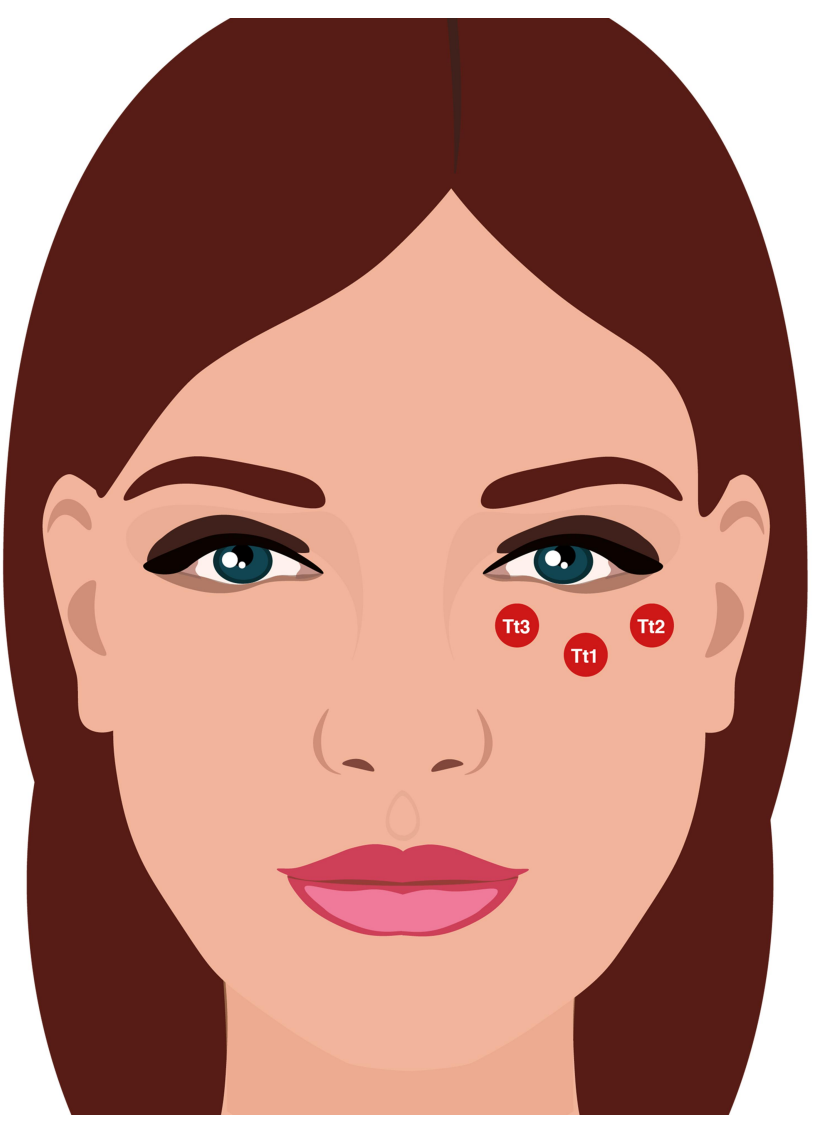

Figure 3 Overview of the different codes involved in the tear trough deformity direct approach treatment. Image courtesy from and reprinted with permission from Allergan plc, Dublin, Ireland. Codes have been adapted from de Maio. ${ }^{10,11}$

Abbreviations: $\mathrm{Tt}$, central infraorbital; Tt2, lateral infraorbital; $\mathrm{Tt} 3$, medial infraorbital.

A HA filler presenting a G' and high cohesivity, such as VYC-25L (Volux ${ }^{\circledR}$; Allergan plc, Dublin, Ireland) or VYC 20L (Voluma ${ }^{\circledR}$; Allergan plc, Dublin, Ireland), in thin skins, may be used. Injection is made by using with a $27 \mathrm{G}$ needle, performing a supraperiosteal bolus of approximately $0.5-0.7 \mathrm{~mL}$. A soft massage, for redistributing the product, is subsequently done.

The clinical effect obtained is the correction of the temporal fossa, at the supraperiosteal level and below the temporal muscle, with elevation of the eyebrow tail, which causes tension in orbicular muscle.

Special attention should be paid to the temporal arteries, which are located at the posterior supraperiosteal level, below the temporal muscle. HA filler injection at point $\mathrm{T} 1$ should be located anterior to the vessels. The location of point $\mathrm{T} 1$ at the level of the fronto-sphenoidal junction is performed by asking the patient to open the mouth. Before injecting, aspiration should be performed as a prophylactic measure and a new needle without filler should be used prior to deep bolus injections. ${ }^{14,15}$

\section{Cheek Region}

In some cases, TTD may be addressed by treating the lateral cheek.

Three different points: $\mathrm{Ck} 1, \mathrm{Ck} 2$, and $\mathrm{Ck} 3$ are treated (see Figure 7).

For treating Ck1, a 27 needle, at supraperiosteal level, should be used. A HA filler, like VYC-20L or VYC-25L, in a $0.3 \mathrm{~mL}$ bolus or 3 microboluses of $0.1 \mathrm{~mL}$ (one in the suture notch and the other two ones to the sides). The 3 microboluses approach provides greater tension than the $0.3 \mathrm{~mL}$ bolus one.

The clinical effect of this Code would be tension at the supraperiosteal level of the zygomaticus major muscle, orbicular and zygomaticus-cutaneous-orbicular retaining ligaments (with canthopexy effect), and myomodulation of the zygomaticus major and orbicularis muscles.

Therapeutic approach of $\mathrm{Ck} 2$ point is made at supraperiosteal level by means a $27 \mathrm{G}$ needle, applying a $0.1-0.2 \mathrm{~mL}$ bolus of a HA filler (VYC-20L) (Figure 7). 

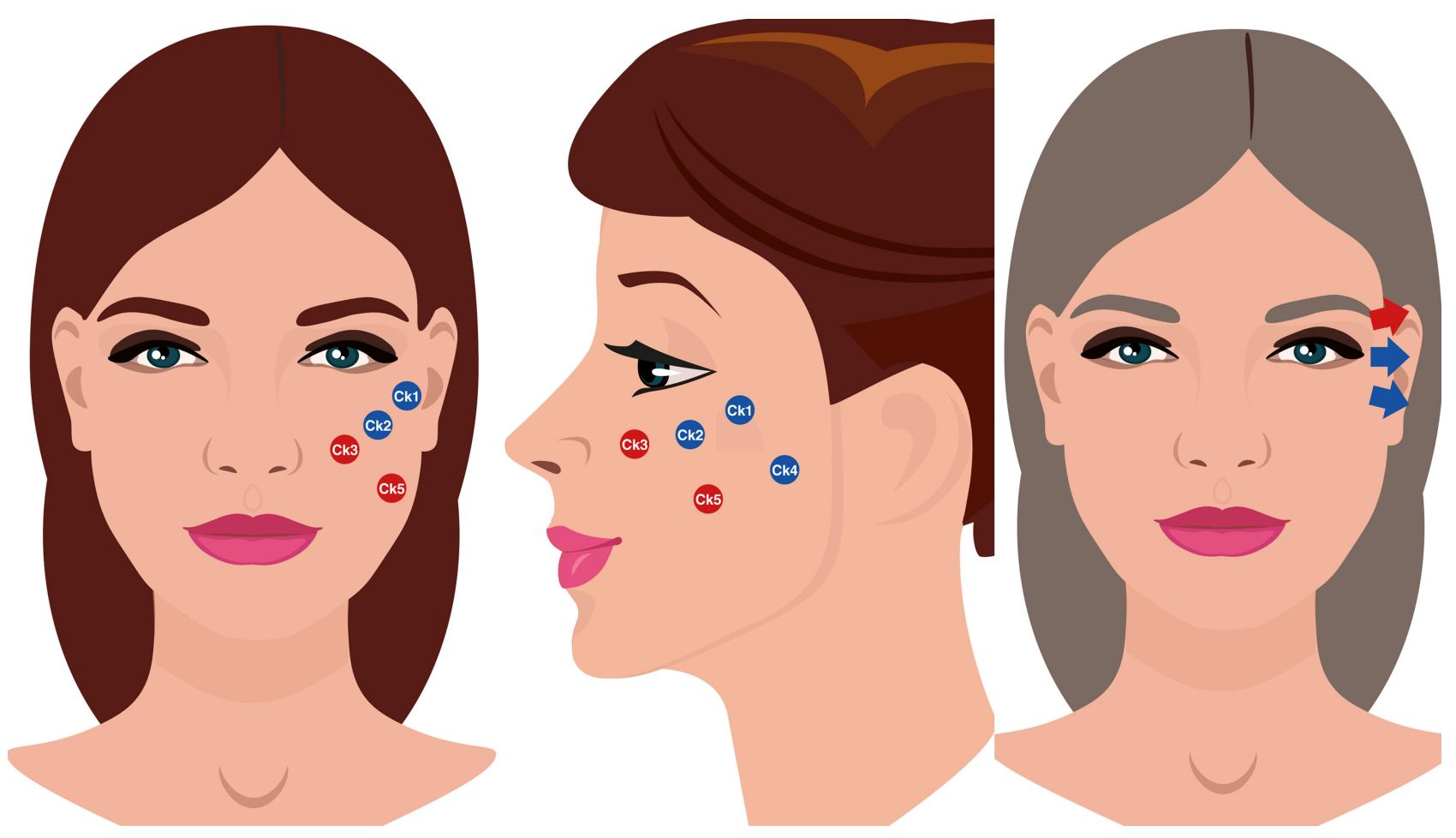

Figure 4 Overview of the different Codes involved in the tear trough deformity indirect approach treatment. Data from Peng et al ${ }^{6}$ and de Maio. ${ }^{10} \mathrm{Image}$ courtesy from and reprinted with permission from Allergan plc, Dublin, Ireland.

Abbreviations: $\mathrm{Ckl}$, zygomatic arch; Ck2, zygomatic eminence; Ck3, anteromedial cheek; Ck4, lateral lower cheek/parotid area; Ck5, submalar/buccal area; OI, central lateral orbital; O2, lower lateral orbital; O3, upper lateral orbital.
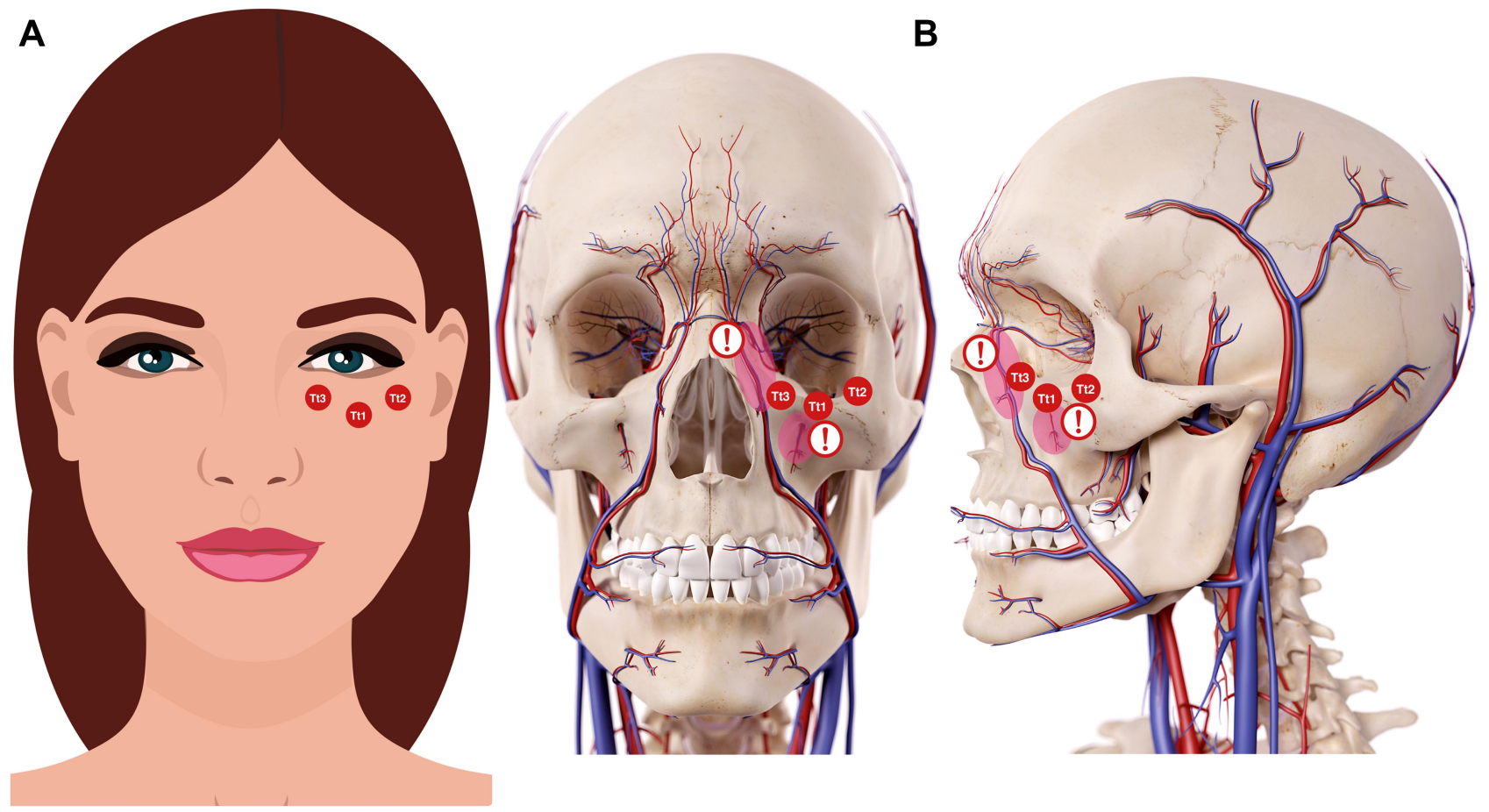

Figure 5 Codes involved in the direct approach strategy for treating tear trough deformity. Tear trough and orbital codes should be reserved for specialists specifically trained in this technique and those who have a sound knowledge of the anatomy and physiology for this particular area. Data from Peng et al ${ }^{6}$ and de Maio. ${ }^{10}$ Image courtesy from and reprinted with permission from Allergan plc, Dublin, Ireland. (A) Imaging representing the frontal view. (B) Imaging representing the anatomical structures. Red circle under TtI and exclamation mark: Be aware of the infraorbital artery branches. Red circle near to Tt3 and exclamation mark: Be aware of the angular artery and vein. Codes have been adapted from de Maio. ${ }^{10,11}$ Abbreviations: Ttl, central infraorbital; Tt2, lateral infraorbital; Tt3, medial infraorbital. 


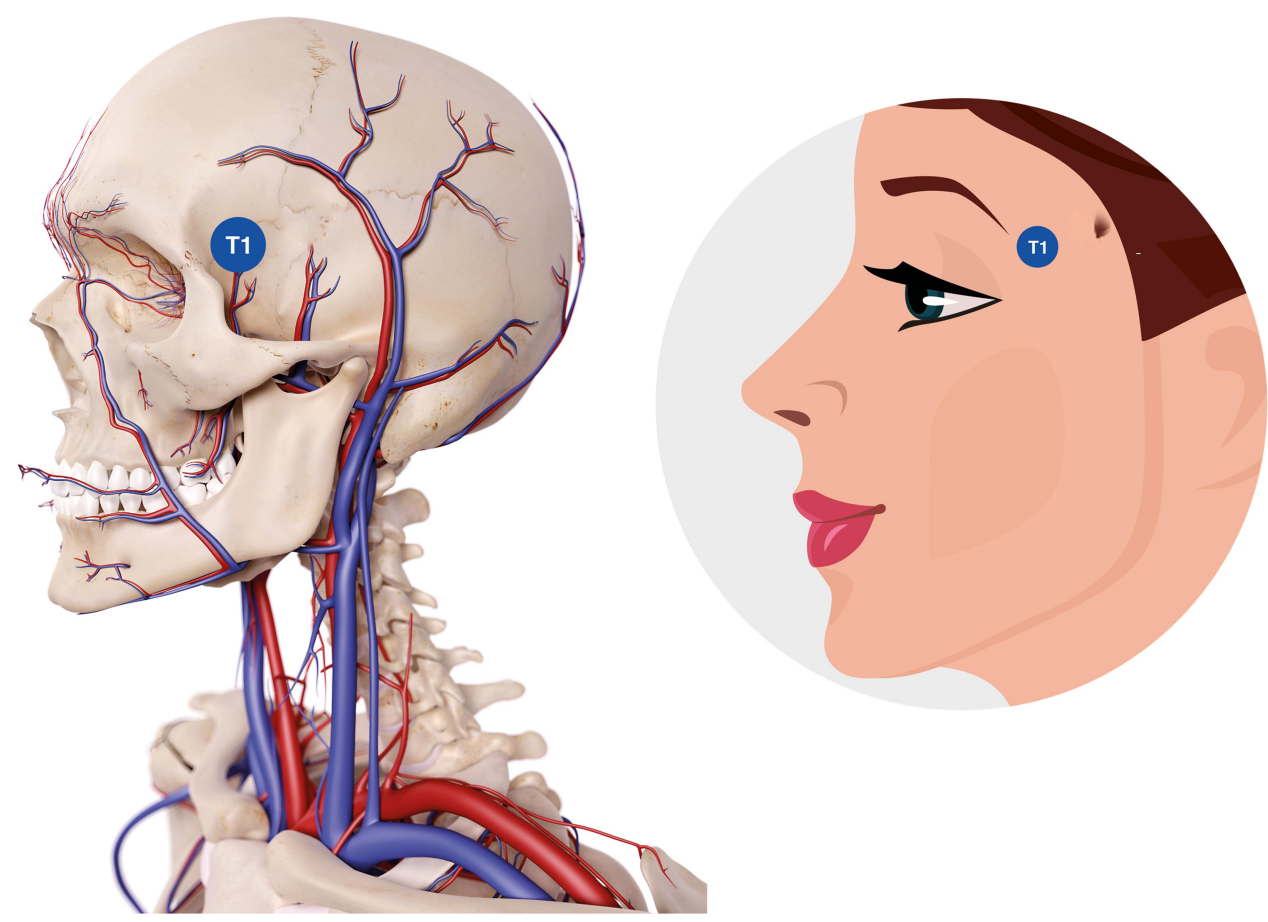

Figure 6 Temporal point to be treated. Data from de Maio. ${ }^{10}$ Image courtesy from and reprinted with permission from Allergan plc, Dublin, Ireland. Abbreviation: TI, anterior temple.
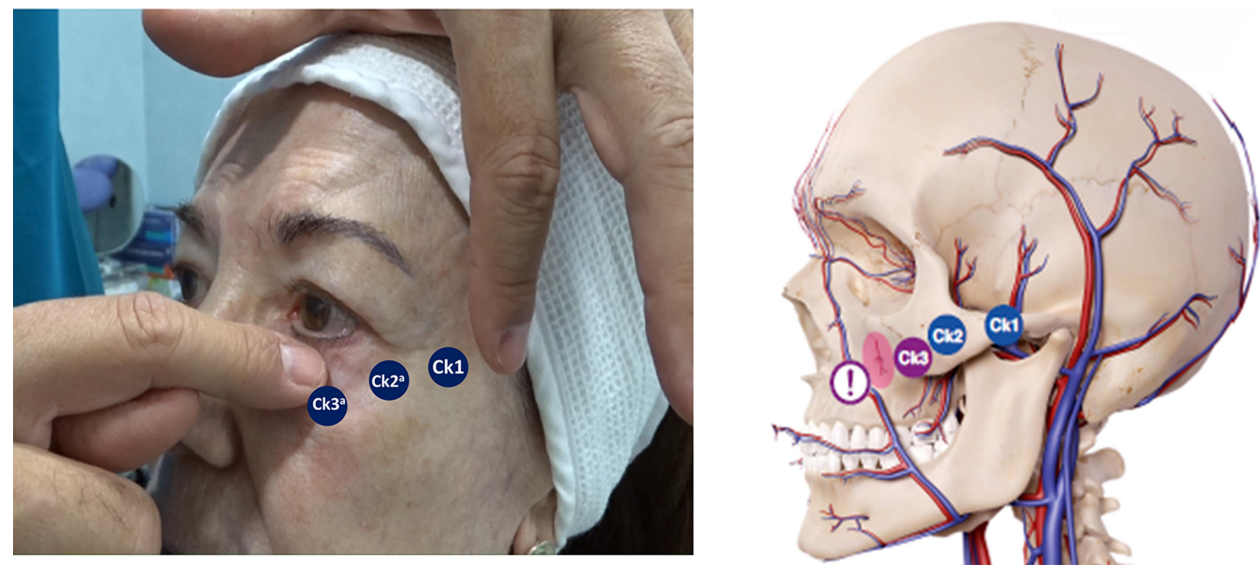

Figure 7 Structural treatment of tear trough deformity. Image courtesy from and reprinted with permission from Allergan plc, Dublin, Ireland. ${ }^{\text {DD }}$ not inject into the cartilage or into the bone, but rather at the level of the cartilage or the level of the bone.

Abbreviations: $\mathrm{Ck}$, cheek; Ckl, zygomatic arch; Ck2, zygomatic eminence; Ck3, anteromedial cheek.

We should be aware of the zygomaticofacial artery. At this point, aspiration is highly recommended before injecting the filler. ${ }^{10}$

The clinical effect on this point would be tautness the muscles zygomaticus minor and levator labii superioris. Additionally, it tightens the zygomatic-cutaneous-orbicularis and the orbitomalar retaining ligaments (with canthopexy effect), as well as myomodulation of the zygomaticus minor, orbicularis, and lip levator muscles inducing latero-facial tension. ${ }^{10,11}$
Ck3 treatment should be done before treating the nasojugal groove. ${ }^{6}$ Its treatment can be performed with $25 \mathrm{G}$ blunt cannula and with $27 \mathrm{G}$ needle.

The treatment of this point is carried out in two phases. The first one is to inject $0.2 \mathrm{~mL}$ to $0.4 \mathrm{~mL}$ of a HA filler of $20 \mathrm{mg} / \mathrm{mL}$ (VYC-20L), at the supraperiosteal level and performing aspiration before injecting the filler. Subsequently, through the same point, we will access to the deep-medial inferior SOOF, by means a $25 / 27 \mathrm{G}$ blunt 
cannula, first at the supraperiosteal level, injecting 0.3 to $0.6 \mathrm{~mL}$ (with a fan technique) of VYC-20L, and injecting afterwards in the same area a more superficial amount of HA either VYC-17.5L (Volbella ${ }^{\circledR}$; Allergan plc, Dublin, Ireland) or VYC-20L, according to the patient needs, under the orbicularis muscle. ${ }^{6,10}$

Injection of VYC-20L or VYC-17.5L depends on the skin thickness and bone structure of the patient. It is important to bear in mind that injecting HA fillers superficially, above the orbicularis muscle, without having provided previously structure to the deep ones, may cause a "squirrel" appearance, which will be increased with facial mimicry. ${ }^{16,17}$

Treatment of this point would induce tautness by increasing volume, at supraperiosteal level, of the zygomaticus minor and levator labii superioris muscles and the zygomatic-cutaneous-orbicularis and orbitomalar retaining ligaments, which cause anterosuperior projection of the cheekbone. Additionally, the treatment of the $\mathrm{Ck} 3$ point induces muscle myomodulation of the zygomaticus minor, orbicularis, and levator labii superioris muscles.
Specialists should be aware of the infraorbital neurovascular bundle, which emerges onto the face through the infraorbital foramen. It is located above the zygomatic process of the maxilla, about $2-3 \mathrm{~cm}$ from the median vertical line of the face. Therefore, aspiration is highly recommended when injecting a $\mathrm{HA}$ filler at this point. ${ }^{6,10,11}$

If nasojugal sulcus needs to be treated, the SOOF approach is crucial. Figure 8 shows an overview of different anatomical structures and the Codes of the periorbital region.

\section{Contour}

Once the treatment of facial structure has been addressed, the second step is to reestablish those facial contours that were lost throughout the facial aging process.

The therapeutic approach of the contours requires special actions on certain static and dynamic facial Codes that, in turn, are based on the structure management performed during the first phase of the treatment.

Once the structural codes at the cheekbones, Ck1, Ck2, and $\mathrm{Ck} 3$ have been addressed (see Structure section), it is

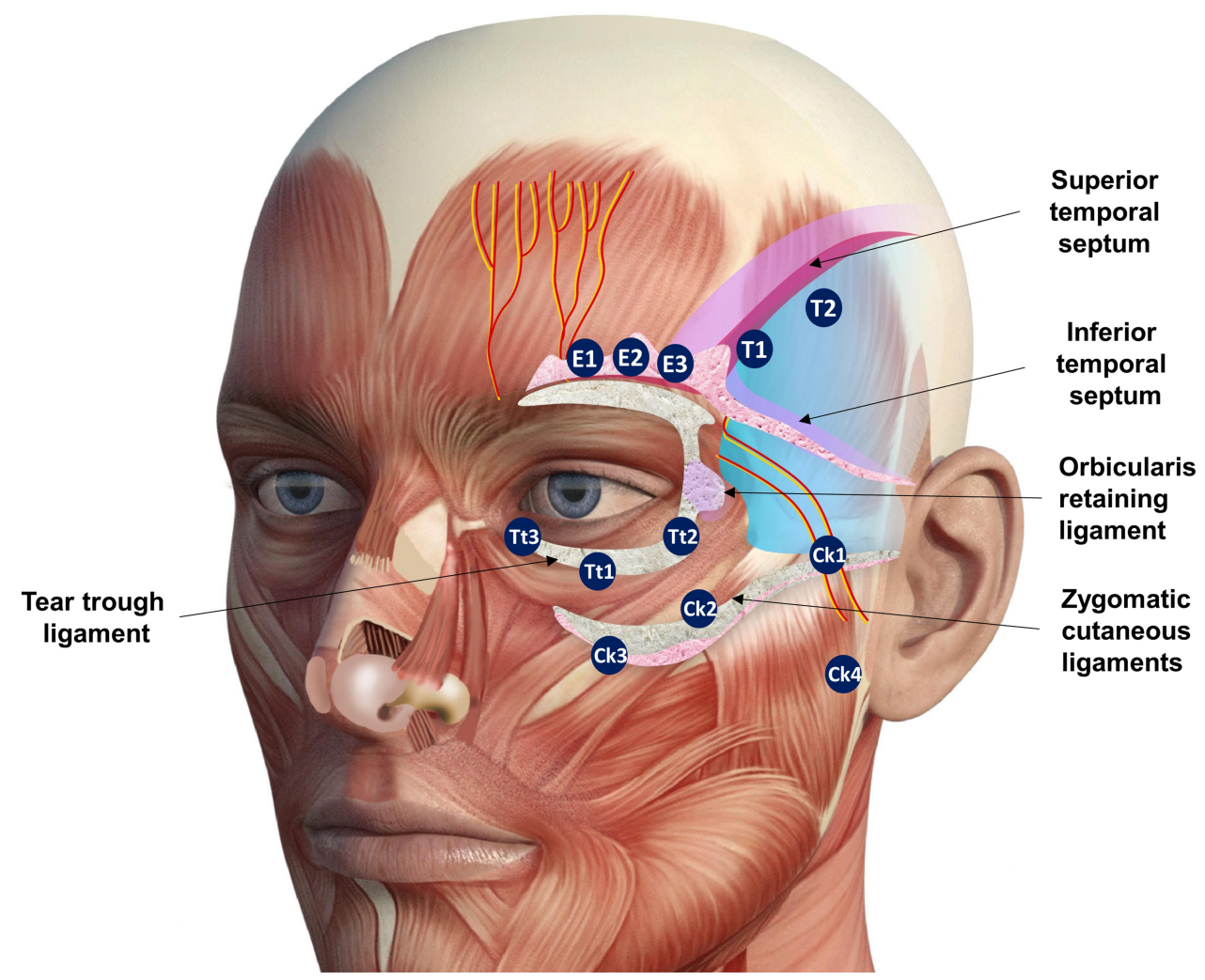

Figure 8 Different anatomical structures and the codes of the periorbital region. Data from de Maio. ${ }^{10}$ Image courtesy from and reprinted with permission from Allergan plc, Dublin, Ireland.

Abbreviations: EI, eyebrow tail; E2, eyebrow center; E3, eyebrow head; TI, anterior temple; T2, posterior temple; CkI, zygomatic arch; Ck2, zygomatic eminence; Ck3, anteromedial cheek; Ck4, lateral lower cheek/parotid area; Ttl, central infraorbital; Tt2, lateral infraorbital; Tt3, medial infraorbital. 
time to integrate the "structural anatomical corrections" into a comprehensive approach more visual and understandable for the patients (Figure 4).

Treatment is usually performed with a $25-27 \mathrm{G}$ blunt cannula, with a fan technique, by using a $20 \mathrm{mg} / \mathrm{mL} \mathrm{HA}$ filler (VYC-20L). Special attention should be paid to the small preauricular and superficial zygomatic vessels, which are frequent in this region. ${ }^{6,10,18}$

Therapeutic approach to $\mathrm{Ck} 5$ Code is subcutaneous, with either VYC-25L or VYC-20L (in patients with thin skin), by means a $25-27 \mathrm{G}$ blunt cannula, with a fan technique, from the oral commissure and upwards towards Ck4. ${ }^{6,10}$ The amount of filler ranges from $0.4 \mathrm{~mL}$ to $0.7 \mathrm{~mL}$ depending on patient's needs. The clinical effect is to provide volume to a lipoatrophic area that becomes evident when the patient sucks or pouts their lips. The HA is injected deep subcutaneous, above the buccinator muscle and under the risorius one, inducing myomodulation in both muscles. ${ }^{6,11}$

The management of these Codes will provide a more contoured appearance of the cheek region, without "steps" in the zygomatic arch area, trying to integrate the restored/ created structure in the facial contour. In men, it is advisable to reinforce the anterior projection of the cheek bone a little bit more. Whereas, in women, the posterior anterolateral projection will determine the beauty.

\section{Refinement}

Refinement is the third step of this comprehensive therapeutic approach and represents its "final touch", once the structure and contour processes have been carried out.

\section{Orbicular Region}

The main purpose of volumizing this area is to recover the supraperiosteal deep fat pockets, which, along with loss of the orbital bone rim, determine the subcutaneous structure of the lateral orbit (Figure 4).

In many patients, TTD causes sagging and superficial dynamic wrinkles due to both a hypercontractility of the orbicularis muscles and a laxity of the orbicular retaining ligament.

The treatment is performed, by administering a supraperiosteal bolus $(0.1-0.15 \mathrm{~mL}$, at each point $\mathrm{O} 1$, O2, O3), of a $15 \mathrm{mg} / \mathrm{mL}$ HA filler (VYC-15L; Volift ${ }^{\circledR}$; Allergan plc, Dublin, Ireland), by means a $30 \mathrm{G}$ needle. ${ }^{6,10,11}$ The objective is to induce myomodulation of the orbicularis muscle and increase the tension of the orbicular retaining ligament, causing a slight canthopexy effect and correcting horizontal wrinkles.
Clinical results, assessed by means photographs, have shown a significant aesthetic improvement (Figures 9 and 10).

There are some Codes that merit a special consideration (Table 7).

As previously mentioned, aspiration is highly recommended when performing injections at a deep level. Additionally, the TTD treatment should be performed only by well-trained and experienced specialists, who have a sound knowledge of the anatomy of this region. $^{10,11}$

\section{Safety}

Adverse events can be divided into early events (occurring up to several days post-treatment) or delayed events (occurring from weeks to years post-treatment). Early events include pain, erythema, etc., while delayed events include orange-brown staining, Tyndall effect, etc. ${ }^{19-23}$ (Tables 8 and 9).

More serious and true complications with fillers include vascular occlusion and necrosis. ${ }^{19-25}$ In the authors' practice, no serious complications, such as arterial embolic accident or necrosis, have occurred.

\section{Discussion}

Since facial aging involves interactions between changes in various anatomic structures (bone, ligaments, muscles, adipose tissue, and skin), ${ }^{3}$ knowledge of age-related anatomy changes is, therefore, crucial for achieving elegant and aesthetically balanced results.

Tear trough deformity is one of the most challenging areas in facial rejuvenation, which requires a comprehensive treatment approach for addressing the different age-related changes that occur at that level. ${ }^{18}$ In younger people TTD is mainly restricted to the tear trough. However, during aging TTD may affect the entire region under the eye.

Many different strategies have been used for addressing TTD treatment. Nevertheless, there is growing interest in techniques that provide a tailored approach towards specific anatomic abnormalities.

Despite HA fillers have been successfully used for correcting periorbital volume loss, their role in addressing TTD combined with eye bags is a relatively new practice. It has been reported that HA fillers may be a valuable option for treating not only periorbital hollowness but also concealed the bulge of infraorbital fat pads. ${ }^{18,26}$ Additionally, it was recently proposed a treatment strategy 


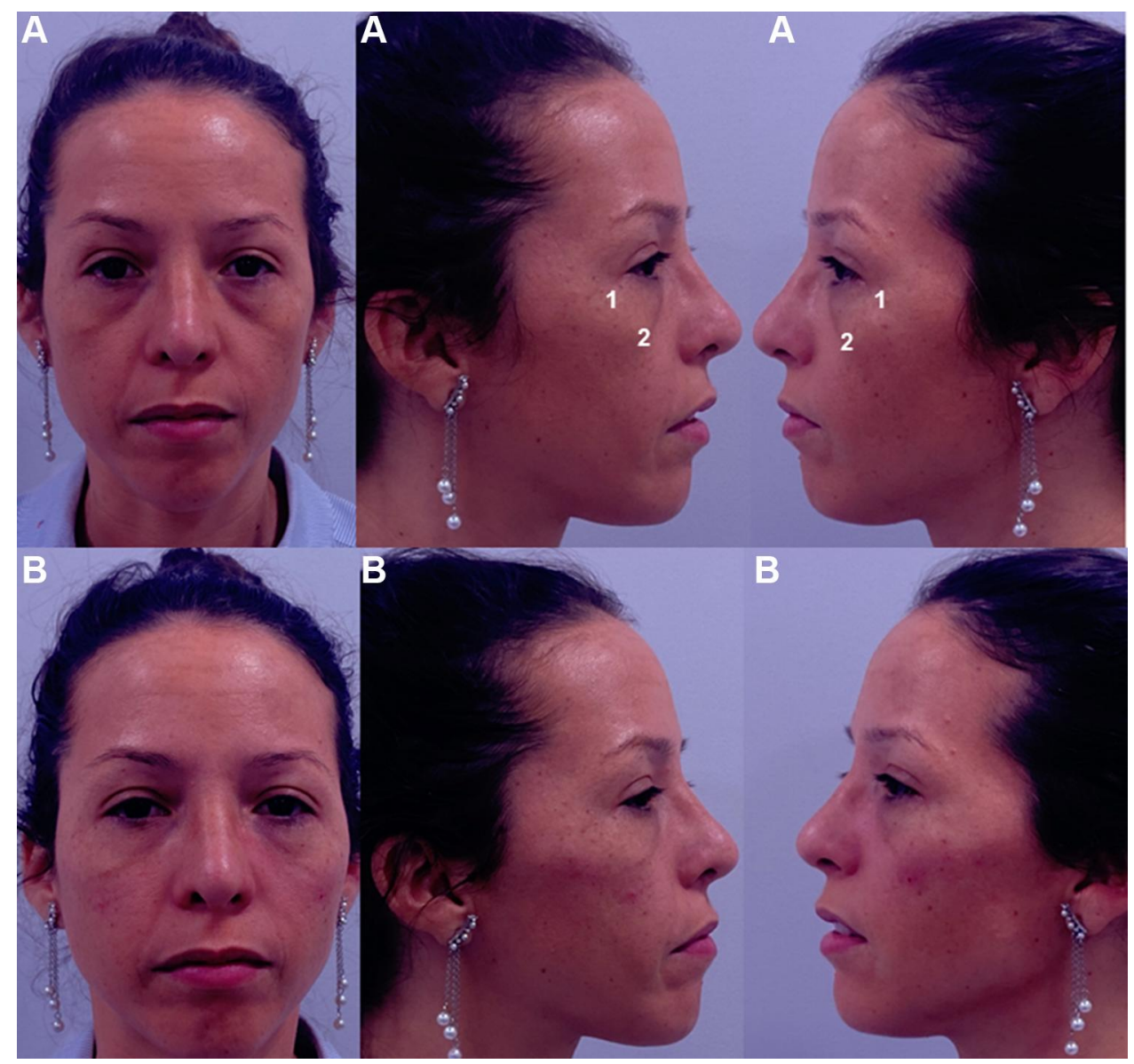

Figure 9 Frontal, right, and left projection of a 40-year-old patient face before (A) and after (B) being treated. The patient provided their consent for the use of their image in this publication. I. Zygomatic arch (Ckl): $0.3 \mathrm{~mL}$ per side of Hyaluronic acid filler (VYC-20L). 2. Anteromedial cheek (Ck3): $0.7 \mathrm{~mL}$ per side of Hyaluronic acid filler (VYC20L). Image courtesy with permission from Dr Farollch. Codes have been adapted from de Maio. ${ }^{10}$

with HA fillers that had into consideration different anatomic aspects of TTD. ${ }^{27}$

We propose two patient-tailored treatment approaches, according to their facial structure. Both, direct and indirect treatment approaches, are based on the Codes. ${ }^{10}$

Direct approach is mainly focus in volumizing tear trough and palpebromalar areas (stages $2 \mathrm{~A}$ and $3 \mathrm{~A}$ of the Belhaouari classification system and Class I in the Hirmand one). It is indicated in patients who present negative snap-tests and have a normal or excessive SOOF volume.

The indirect approach is indicated in those cases who require a comprehensive strategy and is based on the sequence: Structure-Contour-Refinement.

Regarding structure, therapeutic strategies should be focused on providing an adequate correction of the agerelated structure loss.
When thinking about contour, it is essential to take into consideration the sexual dimorphism in human facial form, which involves both size and shape variations of the soft tissue structures. ${ }^{28}$ These contours will require special actions on certain facial areas. ${ }^{10}$ However, it should be considered that previous actions on structure could have been done, which might have already modified the facial contour.

Once the structure and contours have been restored, refinement represents the "final touch" of the treatment. At this time, those "details" that were not corrected when treating structure and contour should be addressed. A proper correction of the small details is going to have a great impact on the aesthetic outcomes and patient satisfaction, even greater than those achieved with the structural or contouring approach. ${ }^{11}$

Structure, contour, and refinement have different Codes assigned to each of them, which will facilitate the systematization of the treatment approaches throughout the process. 


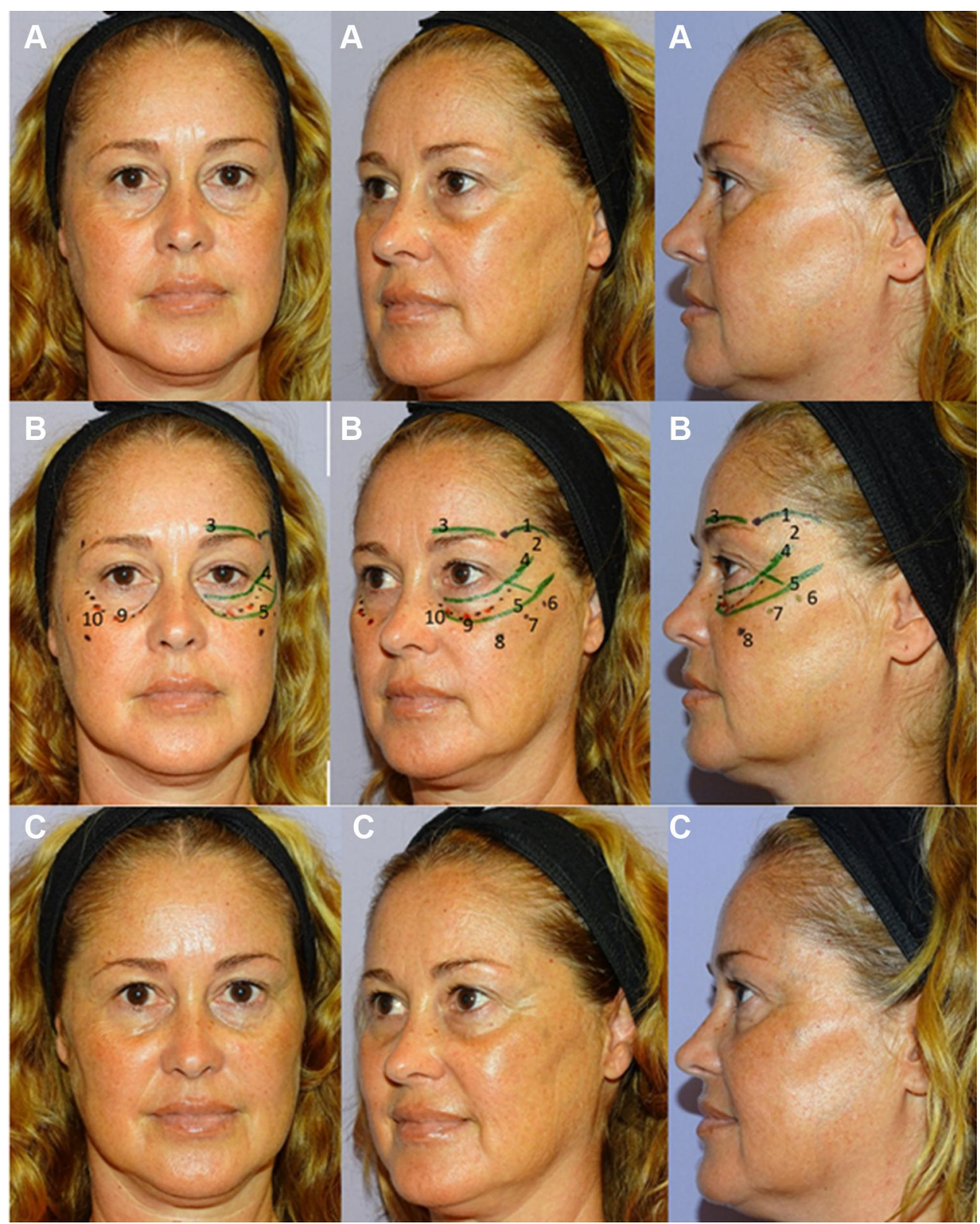

Figure 10 Forty-five years old women with a tear trough deformity (according to Belhaouari classification: IB (see reference 7)) before treatment (A); that shows the treatment plan (B); and after treatment (C). The patient provided their consent for the use of their image in this publication. I. Temporo-orbicular cutaneous retaining ligament; 2. Anterior temple (TI); 3. Palpebral ligament; 4. Orbicular retaining ligament; 5. Zygomatic-cutaneous-orbicularis retaining ligament; 6. Zygomatic arch (CkI); 7. Zygomatic eminence (Ck2); 8. Anteromedial cheek (Ck3); 9. Central infraorbital (Ttl); I0. Medial infraorbital ( $\mathrm{Tt} 3$ ). $\mathrm{TI}$ (2): $0.5 \mathrm{~mL}$ per side of Hyaluronic acid (HA) filler (VYC-25L; Volux ${ }^{\circledR}$; Allergan plc, Dublin, Ireland). CKI (6): 3 microboluses of $0.1 \mathrm{~mL}$ (one in the suture notch and the other two ones to the sides) of HA filler (VYC-20L). Ck2 (7): $0.1 \mathrm{~mL}$ of HA filler (VYC-20L). Ck3 (8): $0.2 \mathrm{~mL}$ lateral + $0.25 \mathrm{~mL}$ medial of HA filler (VYC-20L). Ttl (9): $0.2 \mathrm{~mL}$ of HA filler (VYC-20L). Tt3 (I0): $0.2 \mathrm{~mL}$ of HA filler (VYC-20L). Image courtesy with permission from courtesy of Dr Urdiales-Gálvez. Codes have been adapted from de Maio. ${ }^{10}$

The Codes represents precise anatomical sites and procedures for the injection of HA fillers, which might easily serve as a platform of communication for clinicians worldwide. ${ }^{10}$

The Codes were designed to address aging changes that are visible at rest. ${ }^{10}$ Their purpose is to improve structure, contour, and refinement.

On the other hand, the MD Dyna Codes ${ }^{\circledR}$ were designed to address dynamic aging changes by mechanical modulation of the muscle and providing a natural appearance during muscle activity. ${ }^{11}$

The lack or the loss of structural support can yield alterations in facial muscles, which affects the balance in activity between them. ${ }^{11,12}$ HA filler treatment may be used to modulate muscle activity, either supporting its movement or reducing its overaction, regardless unbalance is due to a structural deficiency or a loss of volume in aging. ${ }^{11,12}$ Mechanical myomodulation refers to the effect 
Table 7 Different Aspects That Need to Be Considered When Injecting Hyaluronic Acid (HA) Fillers for Treating Tear Trough Deformity. Adapted from de Maio

\begin{tabular}{|l|l|}
\hline MD Code & \multicolumn{1}{|c|}{ Special Consideration } \\
\hline TI & Pay attention to the superficial frontal artery and the deep temporal arteries. \\
\hline Ckl & None \\
\hline Ck2 & Pay attention to the zygomaticofacial artery \\
\hline Ck3 & Pay attention to the infraorbital artery \\
\hline Ttl & Pay attention to the infraorbital artery branches \\
\hline Tt2 & None \\
\hline Tt3 & Pay attention to the angular artery and vein \\
\hline
\end{tabular}

Note:Data from these studies. ${ }^{10,11}$

Abbreviations: TI, anterior temple; CkI, zygomatic arch; Ck2, zygomatic eminence; Ck3, anteromedial cheek; Ttl, central infraorbital; Tt2, lateral infraorbital; Tt3, medial infraorbital.

Table 8 Overview of the Adverse Events Associated with the Use of Dermal Fillers. Adapted from Funt and Pavicic

\begin{tabular}{|c|c|c|}
\hline & Early Adverse Events ${ }^{a}$ & Delayed Adverse Events ${ }^{b}$ \\
\hline Injection site reactions ${ }^{c}$ & $\begin{array}{l}\text { Erythema } \\
\text { Edema } \\
\text { Pain/tenderness } \\
\text { Bruising } \\
\text { Itching }\end{array}$ & $\begin{array}{c}\text { Erythema } \\
\text { Edema } \\
\text { Pain/tenderness } \\
\text { Nodule/abscess } \\
\text { Systemic responses } \\
\text { Biofilm }\end{array}$ \\
\hline Infection & $\begin{array}{c}\text { Erythema } \\
\text { Edema } \\
\text { Pain/tenderness } \\
\text { Acne papule formation } \\
\text { Nodule/abscess }\end{array}$ & Foreign body granuloma ${ }^{d}$ \\
\hline Hypersensitivity & $\begin{array}{c}\text { Erythema } \\
\text { Edema } \\
\text { Pain/tenderness } \\
\text { Non-fluctuant nodules }\end{array}$ & Migration of filler material \\
\hline Technical and placement errors & $\begin{array}{c}\text { Lumps } \\
\text { Asymmetries } \\
\text { Contour irregularities } \\
\text { Dysesthesias, paresthesias, and anesthesia }\end{array}$ & $\begin{array}{l}\text { Immune reactions } \\
\text { Dysesthesias, paresthesias, and anesthesia }\end{array}$ \\
\hline Skin discoloration & $\begin{array}{c}\text { Redness } \\
\text { Whiteness } \\
\text { Hyperpigmentation }\end{array}$ & $\begin{array}{l}\text { Persistent discoloration } \\
\text { Persistent scarring }\end{array}$ \\
\hline Vascular compromise ${ }^{\mathrm{e}}$ & $\begin{array}{l}\text { Blurred vision } \\
\text { Loss of vision }\end{array}$ & Tissue necrosis \\
\hline
\end{tabular}

Notes: ${ }^{a}$ Occurring up to several days post-treatment. ${ }^{b}$ Occurring from weeks to years post-treatment. ${ }^{c}$ Atypical as delayed adverse events. ${ }^{d}$ Varying from subclinical histologic changes to disfiguring nodules. ${ }^{e}$ Retinal artery occlusion. Data from these studies. ${ }^{19-21,23}$ 
Table 9 Overview of the Early and Delayed Adverse Events in Patients Who Underwent Tear Trough Deformity Treatment with Hyaluronic Acid (HA) Fillers

\begin{tabular}{|c|c|}
\hline \multicolumn{2}{|r|}{ Early Adverse Events } \\
\hline Event & Prevention/Treatment \\
\hline Pain & To use HA fillers with lidocaine \\
\hline Erythema & N.A. \\
\hline Swelling/Bruising & $\begin{array}{l}\text { To avoid all blood-thinning medications. } \\
\text { Fillers that incorporate lidocaine and epinephrine (adrenaline) may reduce the amount of postinjection bruising. } \\
\text { To apply firm pressure and ice packs before and after the treatment session. }\end{array}$ \\
\hline Asymmetry & N.A. \\
\hline Migraine & N.A. \\
\hline \multicolumn{2}{|r|}{ Delayed Adverse Events } \\
\hline Event & Prevention/Treatment \\
\hline Orange-brown staining & $\begin{array}{l}\text { Preinjection ice application. } \\
\text { Proper depth of injection. } \\
\text { Discontinuation of anticoagulants at least seven days before injection. }\end{array}$ \\
\hline $\begin{array}{l}\text { Postinflammatory } \\
\text { hyperpigmentation }\end{array}$ & It is usually associated with dark skin types due to bruising and hematoma. It can be difficult to treat \\
\hline Puffiness & Its incidence may be reduced by proper patient and filler selection. \\
\hline Infections & $\begin{array}{l}\text { Filler injections should not be performed if there is an infection in the adjacent site. } \\
\text { It can be treated with antibiotics active against frequent skin bacteria including Staphylococcus epidermidis or } \\
\text { Propionibacterium acnes. }\end{array}$ \\
\hline The Tyndall effect & $\begin{array}{l}\text { It occurs when particulate HA fillers are inappropriately implanted into the superficial dermis or epidermis. } \\
\text { Hyaluronidase should be the initial approach to treatment. }\end{array}$ \\
\hline Nodules & $\begin{array}{l}\text { They can be treated with local massage, aspiration or incision and drainage of the product. } \\
\text { Hyaluronidase can be used to dissolve a nodule or a focus of overcorrection. }\end{array}$ \\
\hline Blindness $^{\mathrm{a}}$ & $\begin{array}{l}\text { To limit the amount of filler bolus injected in one site. One way to do this is to use blunt cannulas. } \\
\text { To apply minimal pressure on the syringe, which decreases the risk of retrograde flow into the retinal arteries. }\end{array}$ \\
\hline
\end{tabular}

Notes: Data from these studies. ${ }^{15,19-23}$ a Retinal artery occlusion is a rare event. ${ }^{24}$

Abbreviations: HA, hyaluronic acid; NA, not applicable.

that the HA fillers have on the function of facial mimetic muscles. ${ }^{11,12}$

Codes of the upper and midface are involved in the treatment of the TTD. ${ }^{29,30}$

A proper selection of HA filler is a crucial point of these treatment approaches. Different manufacturingrelated factors, including HA concentration, polymer chain length, crosslinking degree, or cross-linking technology are going to influence significantly on different filler properties, such as requisite needle size; particle size; duration; extrusion force; and elastic Modulus (G'), which will critically influence product selection and indication. ${ }^{31-33}$ For example, VYC-25L, VYC-20L, and VYC-17.5L, for their rheologic characteristics, are specially indicated for addressing structural deficiencies, ${ }^{27}$ whereas VYC-15L is more indicated for refining. ${ }^{26,27}$

Regarding safety, as indications for HA fillers expand, the number and spectrum of adverse events will increase. Most adverse events of HA fillers are mild and transient. However, more serious adverse events can occur, leaving patients with long-lasting or permanent functional and aesthetic defects. $^{15,19-21,23}$

Correction of a TTD with nonsurgical techniques presents unique challenges. Unlike other facial hollows (such as the nasolabial folds, which are easily 
camouflaged), the tear trough requires more technically demanding treatment due to the breadth of the hollow, skin quality changes (thinning), and the presence of adjacent orbital fat pads. ${ }^{2,14}$

As limitation, need to be mentioned that the current article presents the personal experience of the authors on a specific subject and this fact should be considered when interpreting data from this paper. Additionally, all the treatments have been done with Vycross ${ }^{\circledR}$ technology products. Appropriate caution is therefore recommended when extending the results to other HA fillers.

\section{Conclusions}

The treatment of TTD should be addressed from a comprehensive perspective, including potential lack of structural support, as well as interventions on the dynamic processes involved in the problem.

Additionally, it should be taken into consideration that TTD was listed as the most challenging area to treat with HA. That is why TTD treatment should be performed only by well-trained and experienced specialists, who have a sound knowledge of the anatomy of this region.

\section{Acknowledgments}

Medical writing and editorial assistant services have been provided by Ciencia y Deporte S.L. and covered by a grant from Allergan. Support for this assistance was funded by Allergan Aesthetics, an AbbVie company.

\section{Author Contributions}

All authors made substantial contributions to conception and design, acquisition of data, or analysis and interpretation of data; took part in drafting the article or revising it critically for important intellectual content; agreed to submit to the current journal; gave final approval of the version to be published; and agree to be accountable for all aspects of the work.

\section{Funding}

Medical writing services has been provided by Allergan Aesthetics, an AbbVie company. Allergan did not participate in either data collection, analysis or redaction of the manuscript. Neither honoraria nor payments were made for authorship.

\section{Disclosure}

Dr Urdiales-Gálvez has received a grant from Allergan Aesthetics, an AbbVie company, for covering the medical writing services. Dr Farollch-Prats has received research grants from Allergan Aesthetics, an AbbVie company.

\section{References}

1. Jiang J, Wang X, Chen R, Xia X, Sun S, Hu K. Tear trough deformity: different types of anatomy and treatment options. Postep Derm Alergol. 2016;33(4):303-308. doi:10.5114/ada.2016.61607

2. Stutman RL, Codner MA. Tear trough deformity: review of anatomy and treatment options. Aesthet Surg J. 2012;32(4):426-440. doi:10.1177/1090820X12442372

3. Cotofana S, Fratila AA, Schenck TL, Redka-Swoboda W, Zilinsky I, Pavicic T. The anatomy of the aging face: a Review. Facial Plast Surg. 2016;32(3):253-260. doi:10.1055/s-0036-1582234

4. Barton FE Jr, Ha R, Awada M. Fat extrusion and septal reset in patients with the tear trough triad: a critical appraisal. Plast Reconstr Surg. 2004;113(7):2115-2121; discussion 2122-2113. doi:10.1097/ 01.PRS.0000122409.00716.34

5. Peng L, Peng J. Treating the tear trough: a new classification system, a 6-step evaluation procedure, hyaluronic acid injection algorithm, and treatment sequences. $J$ Cosmet Dermatol. 2018;17(3):333-339. doi:10.1111/jocd.12514

6. Belhaouari L, Gassia V, Lauwers F. J. Dynamique et embellissement du mid-faceMéd. Esth Et Chir Derm. 2014;XXXXI(164):203-209.

7. Authors no listed. The international study on aesthetic/cosmetic procedures performed in 2018. Available from: https://www.isaps.org/ wp-content/uploads/2019/12/ISAPS-Global-Survey-Results-2018new.pdf. Last accessed January 7, 2021.

8. de Maio M. MD Codes ${ }^{\mathrm{TM}}$ : a methodological approach to facial aesthetic treatment with injectable hyaluronic acid fillers. Aesthetic Plast Surg. 2020;22.

9. de Maio M. Myomodulation with injectable fillers: an innovative approach to addressing facial muscle movement. Aesthetic Plast Surg. 2018;42(3):798-814. doi:10.1007/s00266-018-1116-Z

10. Hirmand H. Anatomy and nonsurgical correction of the tear trough deformity. Plast Reconstr Surg. 2010;125(2):699-708. doi:10.1097/ PRS.0b013e3181c82f90

11. Belhaouari L, Quinodoz P, Prevot A. Myomodulation et acide hyaluronique. J Méd Esth Et Chir Derm. 2019;XXXXVI(183):219-225.

12. de Maio M. Myomodulation with injectable fillers: an update. Aesthetic Plast Surg. 2020;44(4):1317-1319. doi:10.1007/s00266020-01768-1

13. Ascher B, Coleman S, Alster T, et al. Full scope of effect of facial lipoatrophy: a framework of disease understanding. Dermatol Surg. 2006;32(8):1058-1069. doi:10.1111/j.1524-4725.2006.32230.x

14. Cotofana S, Steinke H, Schlattau A, et al. The anatomy of the facial vein: implications for plastic, reconstructive, and aesthetic procedures. Plast Reconstr Surg. 2017;139(6):1346-1353. doi:10.1097/PRS.0000000000003382

15. Urdiales-Gálvez F, Delgado NE, Figueiredo V, et al. Preventing the complications associated with the use of dermal fillers in facial aesthetic procedures: an expert group consensus Report. Aesthetic Plast Surg. 2017;41(3):667-677. doi:10.1007/s00266-017-0798-y

16. Carruthers J, Carruthers A, Tezel A, Kraemer J, Craik L. Volumizing with a $20-\mathrm{mg} / \mathrm{mL}$ smooth, highly cohesive, viscous hyaluronic acid filler and its role in facial rejuvenation therapy. Dermatol Surg. 2010;36(Suppl 3):1886-1892. doi:10.1111/j.15244725.2010.01778.x 
17. Baumann L, Narins RS, Beer K, et al. Volumizing hyaluronic acid filler for midface volume deficit: results after repeat treatment. Dermatol Surg. 2015;41(Suppl 1):S284-292. doi:10.1097/ DSS.0000000000000541

18. Sharad J. Treatment of the tear trough and infraorbital hollow with hyaluronic acid fillers using both needle and cannula. Dermatol Ther. 2020;33(3):e13353. doi:10.1111/dth.13353

19. Funt D, Pavicic T. Dermal fillers in aesthetics: an overview of adverse events and treatment approaches. Clin Cosmet Investig Dermatol. 2013;Dec(6):295-316.

20. Funt D, Pavicic T. Dermal fillers in aesthetics: an overview of adverse events and treatment approaches. Plast Surg Nurs. 2015;35 (1):13-32. doi:10.1097/PSN.0000000000000087

21. Urdiales-Gálvez F, Delgado NE, Figueiredo V, et al. Treatment of soft tissue filler complications: expert consensus recommendations. Aesthetic Plast Surg. 2018;42(2):498-510. doi:10.1007/s00266-0171063-0

22. Sharad J. Dermal fillers for the treatment of tear trough deformity: a review of anatomy, treatment techniques, and their outcomes. J Cutan Aesthet Surg. 2012;5(4):229-238. doi:10.4103/0974-2077.104910

23. Philipp-Dormston WG, Goodman GJ, De Boulle K, et al. Global approaches to the prevention and management of delayed-onset adverse reactions with hyaluronic acid-based fillers. Plast Reconstr Surg Glob Open. 2020;8(4):e2730. doi:10.1097/GOX.0000000000002730

24. Peter S, Mennel S. Retinal branch artery occlusion following injection of hyaluronic acid (Restylane). Clin Experiment Ophthalmol. 2006;34(4):363-364. doi:10.1111/j.1442-9071.2006.01224.x

25. Beleznay K, Humphrey S, Carruthers JD, Carruthers A. Vascular compromise from soft tissue augmentation: experience with 12 cases and recommendations for optimal outcomes. $J$ Clin Aesthet Dermatol. 2014;7(9):37-43.
26. Goel A, Sethi P. Concealing of under eye orbital fat pads with hyaluronic acid filler: a case report. J Cosmet Dermatol. 2020;19 (4):820-823. doi:10.1111/jocd.13097

27. Peng HP, Peng JH. Treating the tear trough-eye bag complex: treatment targets, treatment selection, and injection algorithms with case studies. J Cosmet Dermatol. 2020;19(9):2237-2245. doi:10.1111/jocd.13622

28. Ferrario VF, Sforza C, Schmitz JH, Miani A Jr, Taroni G. Fourier analysis of human soft tissue facial shape: sex differences in normal adults. J Anat. 1995;187(Pt 3):593-602.

29. de Maio M, Swift A, Signorini M, Fagien S. Aesthetic leaders in facial aesthetics consensus committee. Facial assessment and injection guide for botulinum toxin and injectable hyaluronic acid fillers: focus on the upper face. Plast Reconstr Surg. 2017;140(2):265e276e. doi:10.1097/PRS.0000000000003544

30. de Maio M, DeBoulle K, Braz A, Rohrich RJ. Alliance for the Future of aesthetics consensus committee. Facial assessment and injection guide for botulinum toxin and injectable hyaluronic acid fillers: focus on the midface. Plast Reconstr Surg. 2017;140(4):540e-550e. doi:10.1097/PRS.0000000000003716

31. Micheels P, Sarazin D, Tran C, Salomon D. Effect of different crosslinking technologies on hyaluronic acid behavior: a visual and microscopic study of seven hyaluronic acid gels. J Drugs Dermatol. 2016;15(5):600-606.

32. Goodman GJ, Swift A, Remington BK. Current concepts in the use of Voluma, Volift, and Volbella. Plast Reconstr Surg. 2015;136(5 Suppl):139S-148S. doi:10.1097/PRS.0000000000001734

33. Pierre S, Liew S, Bernardin A. Basics of dermal filler rheology. Dermatol Surg. 2015;41(Suppl1):S120-126. doi:10.1097/ DSS.0000000000000334

\section{Publish your work in this journal}

Clinical, Cosmetic and Investigational Dermatology is an international, peer-reviewed, open access, online journal that focuses on the latest clinical and experimental research in all aspects of skin disease and cosmetic interventions. This journal is indexed on CAS
The manuscript management system is completely online and includes a very quick and fair peer-review system, which is all easy to use. Visit http://www.dovepress.com/testimonials.php to read real quotes from published authors. 